\title{
Microphthalmia Transcription Factor
}

\section{A Sensitive and Specific Melanocyte Marker for Melanoma Diagnosis}

Roy King, ${ }^{*}$ Katherine N. Weilbaecher, ${ }^{\dagger}$ Gaël McGill, ${ }^{\dagger}$ Edward Cooley, ${ }^{*}$ Martin Mihm, ${ }^{* \neq}$ and David E. Fisher ${ }^{\dagger}$

From the Department of Dermatopathology," Albany Medical Center, Albany, New York; the Division of Pediatric Oncology, ${ }^{\dagger}$ Dana Farber Cancer Institute and Children's Hospital, Boston, Massachusetts; and the Department of Dermatopathology, Massachusetts General Hospital, Boston, Massachusetts

Malignant melanomas do not uniformly retain expression of melanocytic gene products-an observation associated with diagnostic dilemmas. Microphthalmia transcription factor (Mitf) is a melanocytic nuclear protein critical for the embryonic development and postnatal viability of melanocytes. It serves as a master regulator in modulating extracellular signals, such as those triggered by $\alpha$-MSH and c-Kit ligand. Because of its central role in melanocyte survival and to assess its potential use as a histopathological marker for melanoma, Mitf expression was examined in histologically confirmed human melanoma specimens. Western blot analysis of melanoma cell lines revealed consistent expression of two Mitf protein isoforms differing by MAP kinase-mediated phosphorylation. In a series of 76 consecutive human melanoma surgical specimens, $100 \%$ stained positively for Mitf with a nuclear pattern of reactivity. In a sideby-side comparison, Mitf staining was positive in melanomas that failed to stain for either HMB- 45 or S-100, the most common currently used melanoma markers. Of 60 non-melanoma tumors, none displayed nuclear Mitf staining and two displayed cytoplasmic staining. Although Mitf does not distinguish benign from malignant melanocytic lesions, for invasive neoplasms it appears to be a highly sensitive and specific histopathological melanocyte marker for melanoma. (Am J Patbol 1999, 155:731-738)

The protein encoded by the microphthalmia $(\mathrm{mi})$ gene is a transcription factor essential to the development and survival of melanocytes. Mouse mutations at the mi locus were first described in the 1940s, ${ }^{1}$ and humans with heterozygous mutations of mi have Waardenburg Syndrome IIA, a condition characterized by a white forelock and deafness. ${ }^{2,3}$ Homozygous mi deficiency in mice produces complete loss of melanocytes in the skin, choroid of the eye, and stria vascularis of the inner ear. The $m i$ gene was cloned several years ago and predicted a DNA binding protein in the helix-loop-helix family ${ }^{4}$ that is homologous to the basic-helix/loop/helix/leucine zipper motif present at the carboxy terminus of the c-myc oncogene. Although this subfamily of transcription factors includes only a small number of proteins (including Mitf and Myc), Mitf does not heterodimerize with Myc, but binds DNA efficiently as a homodimer. Biochemical studies also revealed that Mitf is capable of transactivating several gene promoters that are regulated by $\mathrm{E}$ box sequence elements, ${ }^{5}$ among which are promoters regulating the pigmentation enzyme genes tyrosinase, TRP1, and TRP2. ${ }^{5-7}$ Recent studies have demonstrated that melanocyte stimulating hormone $(\alpha-\mathrm{MSH})$ up-regulates pigment enzyme gene expression through a signaling cascade that stimulates expression of Mitf followed by secondary (Mitf-mediated) activation of pigment enzyme expression. 8,9

Although Mitf is important in regulating the pigmentation response for melanocytes, the complete absence of melanocytes in Mitf-deficient mice suggests that Mitf is essential for melanocyte development, postnatal survival, or both. One instructive mouse mutant, mivit, displays nearly normal melanocyte development but accelerated age-dependent melanocyte death over the first months of life. ${ }^{10}$ This melanocyte death is attributable to a mutation within the helix-loop-helix motif of $m i^{5,11}$ and suggests a vital role for Mitf protein in postnatal survival of melanocytes.

Recent studies have also demonstrated that Mitf is a phosphorylation target in the Steel/c-Kit signaling pathway, ${ }^{12}$ a connection that highlights the phenotypic over-

Supported by a grant from the National Institutes of Health to D. E. F. K. N. W. was supported by National Institutes of Health K08 National Institute on Aging 00852-01. G. M. is a predoctoral fellow of the Howard Hughes Medical Institute and a Sandoz fellow. D. E. F. is a Pew Foundation Fellow and James S. McDonnell Scholar.

Accepted for publication April 27, 1999.

R. K. and K. N. W. contributed equally to this manuscript.

Address reprint requests to Dr. David E. Fisher, Division of Pediatric Oncology, Dana Farber Cancer Institute, 44 Binney Street, Boston, Massachusetts 02115. E-mail: david fisher@dfci.harvard.edu. 
lap of $\mathrm{mi} / \mathrm{mi}$, kit, and steel mutant mice. Stimulation of the mitogenic cytokine receptor c-Kit results in MAP kinasemediated phosphorylation of Mitf, producing transcriptional superactivation through selective recruitment of $\mathrm{CBP} / \mathrm{p} 300,{ }^{13}$ a family of factors that function as transcriptional coactivators for Mitf. ${ }^{14,15}$

The annual incidence of human melanoma worldwide is increasing at the rate of approximately $5 \%$ per year. ${ }^{16}$ It is estimated that 1 in 75 persons born in the United States by the year 2000 will develop malignant melanoma in their lifetime. ${ }^{17}$ Due to its propensity to metastasize rapidly and widely, coupled to the common feature of late recurrence, relapses from melanoma represent an important and often life-threatening clinical condition. ${ }^{18}$

Melanoma resides among the tumor types more commonly associated with metastases lacking an obvious primary tumor site. ${ }^{18-22}$ A significant limitation associated with the histopathology of metastatic melanoma is its frequent nonspecific histological appearance, shared with other poorly differentiated neoplasms, combined with common loss of melanocytic markers within these tumors. Pigmentation enzymes and other melanocytic markers such as c-Kit are frequently absent or difficult to detect in primary or metastatic melanomas. ${ }^{23-26}$ Current histopathological diagnosis of metastatic melanoma relies most often on two antibody-antigen combinations: S100 and HMB-45. ${ }^{27-31}$ S100, although quite sensitive, also stains a significant number of nonmelanoma malignancies, ${ }^{23,29}$ thereby providing limited specificity. HMB45 , which is quite selective for melanoma, may fail to identify a fraction (ranging from 5 to $50 \%$ ) of these tumors $^{23,29}$ and has been suggested to stain variably in a technique-dependent fashion. ${ }^{23,27,30,32-35}$ A combination of S100 and HMB45 staining improves their diagnostic utility for melanoma detection.

Using a monoclonal antibody generated against human Mitf, we identified strong nuclear staining within normal skin melanocytes, nevi, dysplastic nevi, and $100 \%$ of 76 consecutively acquisitioned melanomas, including amelanotic and metastatic tumors. In side-byside comparisons, Mitf definitively stained melanomas that were negative for S100 or HMB-45. Among nonmelanoma tumors, Mitf stained the cytoplasm in two of 60 cases, but no cases exhibited nuclear staining. Thus, Mitf may be a sensitive and specific melanocytic marker, offering a useful means of identifying the melanocytic nature of a neoplasm.

\section{Materials and Methods}

\section{Cell Lines}

NIH3T3 murine fibroblast cell line, B16 murine melanoma cell line, and the human neuroblastoma cell lines IMR-32 and SK-N-SH were grown in DMEM with $10 \%$ fetal bovine serum (FBS). The human melanoma cell lines (gift of Dr. R. Halaban, Yale University) 501-mel, ${ }^{24} \mathrm{MeWo}$, and YUZAZ6 $^{36}$ were grown in Ham's F10 media supplemented with $10 \%$ FBS.

\section{Reverse Transcription-Polymerase Chain Reaction (RT-PCR)}

Total cellular RNA was isolated using RNAzol (Tel-Test, Friendswood, TX). Primers to the mouse microphthalmia gene flanking exons 5-8 were synthesized: $5^{\prime}$ exon 5 CCCGTCTCTGGAAACTTGATCG and $3^{\prime}$ exon 8 CTGTACTCTGAGCAGCAGGTG. cDNA was made using MMTV reverse transcriptase (GIBCO BRL, Gaithersburg, $M D)$. Ten micrograms of total RNA were used for each cDNA reaction along with $30 \mathrm{pmol}$ of $3^{\prime}$ exon 8 primer and incubated according to manufacturer's instructions. The cDNA reaction mixture was diluted in PCR buffer (10 $\mathrm{mmol} / \mathrm{L}$ Tris, $\mathrm{pH} 8.3,55 \mathrm{mmol} / \mathrm{L} \mathrm{KCl}, 625$ fmoles of 5 ' primer, 250 fmoles of $3^{\prime}$ primer), Taq polymerase (Fisher Scientific Co., Pittsburgh, PA), and dNTPs (Pharmacia Biotech, Piscataway, NJ) with incubations at $94^{\circ} \mathrm{C}$ for 2 minutes, $57^{\circ} \mathrm{C}$ for 1 minute, and $72^{\circ} \mathrm{C}$ for 2 minutes for 30 cycles and visualized on polyacrylamide gels. ${ }^{37}$

\section{Western Blotting}

Whole cell lysates were made by on-plate lysis of washed cells by adding $2.3 \%$ sodium dodecyl sulfate (SDS), $10 \%$ glycerol, $6.25 \mathrm{mmol} / \mathrm{L}$ Tris, $\mathrm{pH} 6.8$, and 2 - $\beta$-mercaptoethanol, and boiled for 5 minutes. The protein lysates were resolved on $8 \%$ SDS-polyacrylamide gels. Proteins were transferred to nitrocellulose with methanol-glycine electrotransfer buffer (Bio-Rad Labs, Hercules, CA). The membrane was blocked in 5\% milk for 1 hour at room temperature. After washing in TBST (10 mmol/L Tris, $\mathrm{pH}$ 7.6, $150 \mathrm{mmol} / \mathrm{L} \mathrm{NaCl}$, and 0.5\% Tween 20), 1:40 dilution of the Mitf antibody (hybridoma culture supernatant) was added for 1 hour at room temperature and developed using goat anti-mouse horseradish peroxidase-conjugated antibody (Cappel, West Chester, PA) and enhanced chemiluminescence (Amersham, Arlington Heights, IL).

\section{Immunofluorescence and Immunohistochemistry}

Mitf monoclonal antibodies ${ }^{12,37}$ were shown not to crossreact with other b-HLH-Zip factors by immunoprecipitation and DNA mobility shift assay ${ }^{37}$ (data not shown). The antibody $\mathrm{C} 5$ recognizes both mouse and human Mitf and was used for Western blotting, whereas antibody D5 recognizes human Mitf only and was used for immunostaining. For staining, cells were grown on glass chamber slides (Fisher Scientific, Pittsburgh, PA) and were fixed with 3\% formaldehyde in phosphate buffered saline (PBS) for 30 minutes. D5 antibody (diluted 1:40) was added for 1 hour. The Vectastain Elite kit (Vector Laboratories, Burlingame, CA) was used for immunohistochemical staining per manufacturer's instructions. The diaminobenzidine reagent (Vector Laboratories) was applied for 2 to 4 minutes. For immunofluorescence, the Cy-3-conjugated goat anti-mouse (Jackson Immunological) was used. Nuclei were stained with $10 \mathrm{ng} / \mathrm{ml}$ DAPI 
(Sigma). All incubations were followed by three washes with $0.1 \%$ Triton $X-100$ in PBS.

\section{Histopathology}

Eighty cases with the diagnosis of melanoma were sequentially selected from the pathology files of the Albany Medical Center Department of Pathology. Of these, four were excluded because of unavailability of adequate lesional tissue. The histopathological material was reviewed by two of the authors (RK and MM) to confirm the diagnoses. Immunohistochemical studies were performed on all cases using formalin-fixed, paraffin-embedded tissue. Sections were cut at $4 \mu \mathrm{m}$, heated at $60^{\circ} \mathrm{C}$, deparaffinized in xylene, and hydrated in a graded series of alcohols. Primary antibodies included polyclonal rabbit antibody S-100 (Ventana, prediluted), mouse monoclonal antibody HMB-45 (Ventana, prediluted), and monoclonal antibody D5 (Mitf antibody, undiluted). Antigen retrieval was performed using microwaving in citrate buffer for the Mitf antibody. Staining was performed with the Ventana ES automated immunohistochemistry system using the Ventana DAB Detection Kit (Ventana Medical Systems) Tissues known to express the antigen of interest were used as positive controls, whereas removal of the primary antibodies in the test tissues were used as negative controls. Only Mitf antibody nuclear staining was regarded as positive, whereas cytoplasmic staining alone was considered a negative result (and was observed in only two breast carcinomas, see Results). S-100 and HMB-45 antibody staining were considered positive if cytoplasmic staining was present. The Fisher Exact test was used for statistical analyses comparing Mitf versus HMB-45 and Mitf versus S100. Sixty nonmelanocytic tumors (detailed below) were selected to test the specificity of Mitf and HMB-45. These selected tumor types have been shown to express S-100. ${ }^{28}$

\section{Results}

To examine Mitf expression in melanomas, an initial survey was undertaken in a series of four melanoma cell lines, three human ${ }^{24,36}$ and one murine. Using reverse transcriptase PCR, bands corresponding to Mitf were identified in all cases. A doublet representing the alternative splice of an 18-bp segment ${ }^{4}$ was observed in each case (Figure 1A) and verified by sequencing. Two human neuroblastoma cell lines, also neural crest-derived tumors, failed to produce Mitf-specific PCR products (Figure 1A). Western blot analysis of 501-mel melanoma cell line extracts (Figure 1B, lanes 2-5) revealed Mitf-specific bands as a doublet migrating at approximately 52 and 56 $\mathrm{kd}$. Prior biochemical studies using two-dimensional phosphotryptic analyses have confirmed the identity of these Mitf bands and determined that these isoforms differ in the presence of a MAP kinase-mediated phosphorylation at serine 73 in the upper migrating species. ${ }^{12}$ Fibroblast extract (Figure 1B, lane 1) lacked the Mitf protein bands. In addition, recombinant Steel factor (c-Kit ligand) triggered a mobility shift from the lower to the

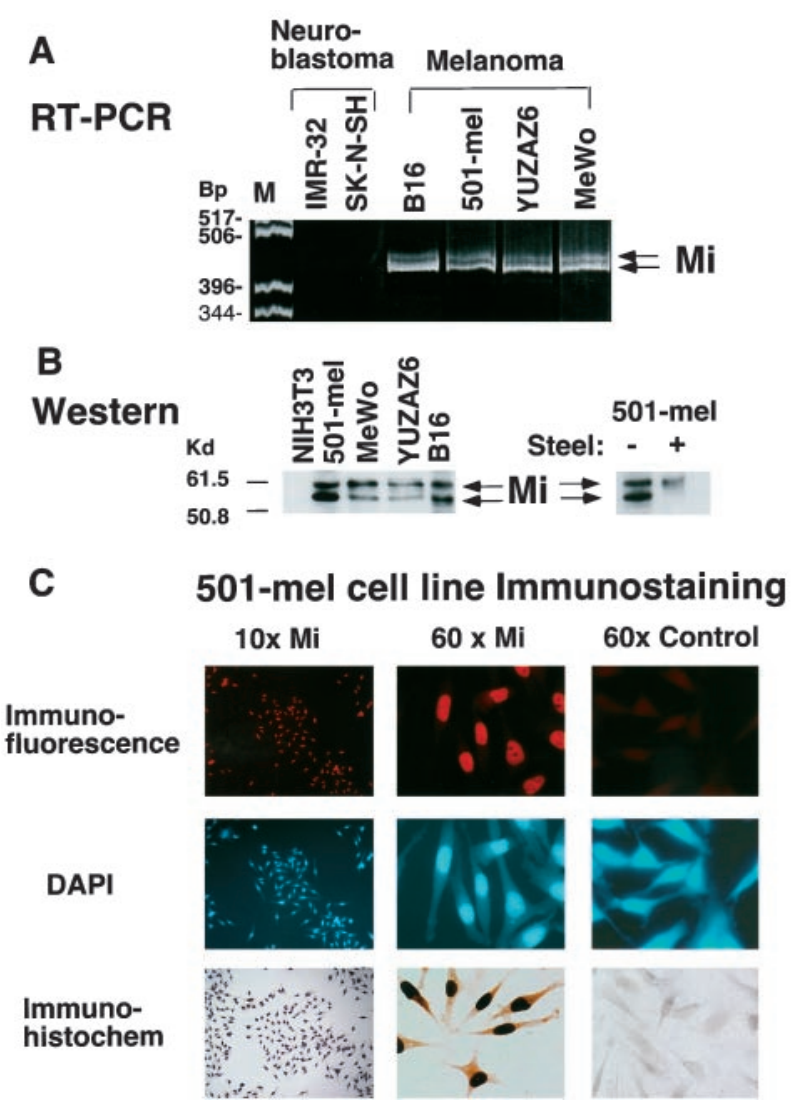

Figure 1. A: RT-PCR of neuroblastoma and melanoma cell lines using primers directed to $\mathrm{Mi}$ (exons 5 to 8 ). The Mi product migrates as a doublet at $432 \mathrm{bp}$ and $448 \mathrm{bp}$ and represents an 18-bp alternative splice ${ }^{11}$ (confirmed by sequencing). Neuroblastoma cell lines were PCR negative while melanomas were PCR-positive. B: Western blot showing 54- and 60-kd melanocyte forms of Mitf protein in the melanoma cell lines 501-mel, ${ }^{12}$ MeWo, Yuzaz, B16. Mitf is absent in NIH3T3. Steel factor (c-Kit ligand) stimulation of the cell line 501-mel causes phosphorylation of the 54-kd species and a mobility shift as previously described. ${ }^{12} \mathrm{C}$ : Immunostaining of the 501-mel melanoma cel line with the D5 Mitf antibody using immunofluorescence and DAB immunohistochemistry showing nuclear stain. Control lacked primary antibody. Original magnifications, $\times 10$ and $\times 60$ (as labeled)

upper migrating form as previously described (Figure 2B, lanes 6 and $7^{12}$ ). Detection of Mitf by RNA or protein analysis was controlled by detection of GAPDH RNA or tubulin protein (data not shown). Direct staining of melanoma cells for Mitf revealed strong nuclear signal by either immunofluorescence or immunohistochemistry (Figure 1C). Two-color fluorescence with DAPI identified nuclei in the same samples (Figure 1C). Thus, Mitf is expressed as a nuclear factor in these melanoma cell lines.

Expression of Mitf was next tested by immunohistochemical staining in normal skin, nevi, dysplastic nevi, and melanomas. Paraffin-embedded tissue samples were stained with Mitf and counterstained with hematoxylin. Control samples from each section were separately stained with hematoxylin and eosin (H\&E) for comparison. Within normal skin, the Mitf specific antibody highlighted nuclear staining within individual melanocytes (Figure 2, see arrows). In addition, melanocytes in 9 benign nevi and 4 dysplastic nevi were positive for Mitf; representative cases are shown in Figure 2. 


\section{Normal Skin}

\section{H\&E}
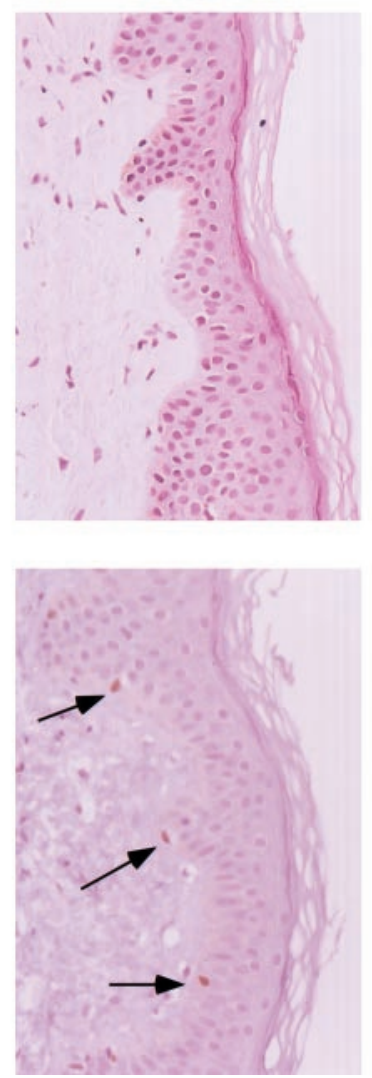

\section{Benign Nevus}
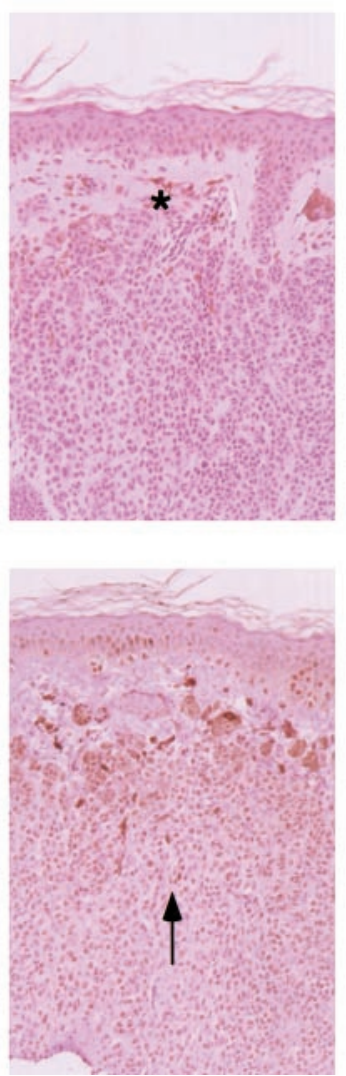

\section{Dysplastic Nevus}
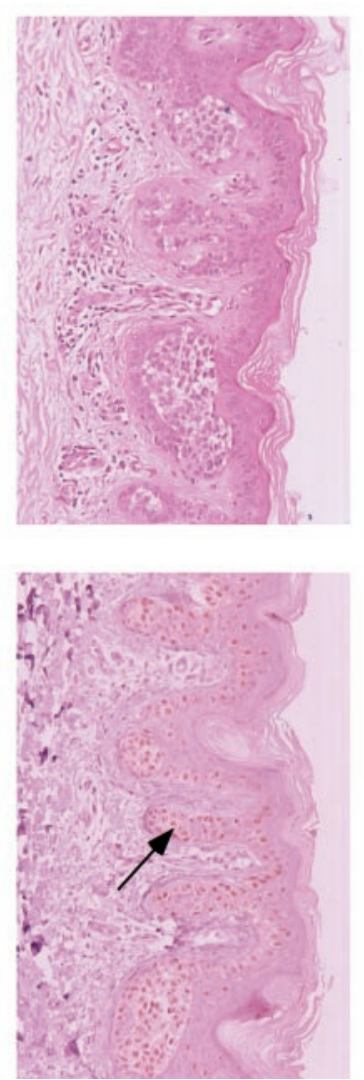

Melanoma
In Situ
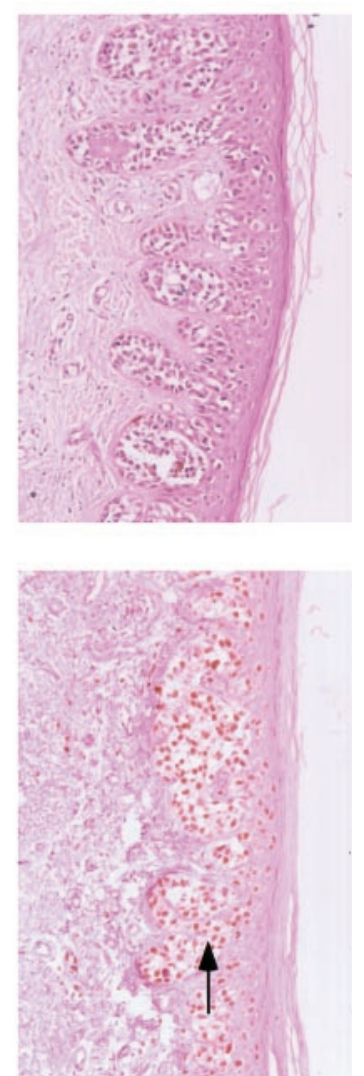

Figure 2. Immunohistochemical staining of normal skin with hematoxylin and eosin (H\&E) and Microphthalmia (Mitf) antibody showing Mitf nuclear staining of normal melanocytes at the epidermal/dermal border. Benign nevus, dysplastic nevus and melanoma in situ show Mitf staining only in the melanocytic component of these lesions $(\mathrm{B} \times 40)$. Arrows indicate areas of Mitf-positive staining. Asterisk indicates endogenous melanin pigment.

Mitf expression was tested in a series of consecutively accessioned histologically confirmed human melanoma pathological specimens. Of the 76 cases, 19 were melanomas in situ, 50 were conventional melanomas, and 7 were metastatic melanomas. Eight cases were histologically amelanotic (2 melanoma in situ and 6 primary melanoma). Nine cases had a predominantly spindled cell morphology, eight cases had a spindled/epithelioid morphology, and the remainder had a predominantly epithelioid cell morphology.

Mitf expression was positive and nuclear in all 19 melanomas in situ (Table 1 and Figure 2). Among the invasive melanomas, Mitf was also positive in all cases, again displaying a nuclear pattern (Table 1). For the consecutive series, Mitf staining was compared in side-by-side fashion with $\mathrm{HMB}-45$ and S-100. The nuclear staining pattern of Mitf contrasted the cytoplasmic or more diffuse staining patterns of S-100 and HMB-45 (Figure 3). All three stains were positive in the majority of cases (Table 1). However, HMB-45 failed to stain 7 cases. In these 76 consecutive melanomas, Mitf's enhanced sensitivity over HMB-45 was statistically significant $(P=0.01)$. Although
S-100 is known to be less specific for melanoma, ${ }^{31}$ all but 5 melanomas in this consecutive series were positive for S-100. Independent of specificity (see below), Mitf displayed a statistical trend toward greater sensitivity for melanoma than $\mathrm{S}-100(P=0.06)$. Only 1 melanoma was negative for both $\mathrm{S} 100$ and $\mathrm{HMB}-45$, and this, too, was

Table 1. Staining Characteristics in 76 Consecutive Melanomas

\begin{tabular}{|c|c|c|c|}
\hline & $\begin{array}{c}\text { Mitf }+ \\
(\% \text { positive) }\end{array}$ & $\begin{array}{l}\text { HMB-45 + } \\
\text { (\% positive) }\end{array}$ & $\begin{array}{c}\text { S-100 + } \\
\text { (\% positive) }\end{array}$ \\
\hline \multicolumn{4}{|l|}{$\begin{array}{c}\text { Consecutive series } \\
\text { of melanomas }\end{array}$} \\
\hline In situ melanoma & $19 / 19$ & $19 / 19$ & $17 / 19$ \\
\hline $\begin{array}{l}\text { Primary } \\
\text { melanoma }\end{array}$ & $50 / 50$ & $44 / 50$ & $48 / 50$ \\
\hline $\begin{array}{l}\text { Metastatic } \\
\text { melanoma }\end{array}$ & $7 / 7$ & $6 / 7$ & $6 / 7$ \\
\hline $\begin{array}{l}\text { All melanomas in } \\
\text { series }\end{array}$ & 76/76 (100) & $69 / 76(91)^{*}$ & * $71 / 76(93)^{\star}$ \\
\hline
\end{tabular}

Asterisks denote statistical comparisons. Mitf was significantly more sensitive than HMB-45 $(P=0.01)$ and displayed a trend relative to $\mathrm{S}$ $100(P=0.06)$ 




Figure 3. Immunohistochemical staining of human melanomas. Conventional melanoma represents a primary melanoma (epidermis and dermis, original magnification, $\times 40)$ stained with hematoxylin and eosin (H\&E), Microphthalmia (Mitf) antibody, HMB-45 antibody and S-100 antibody. Amelanotic refers to an unpigmented melanoma (original magnification, $\times 60$ ). Metastatic refers to a melanoma metastasis within a lymph node (original magnification, $\times 60$ ). In Transit refers to a case of primary melanoma with deep dermal invasion without contiguous epidermal involvement shown at low $(\times 10)$ and high $(\times 60)$ power.

positive for Mitf. Focal positivity was seen within 2 cases for Mitf and 2 cases for HMB-45. Figure 3 shows representative staining for Mitf, HMB-45, and S-100 in conventional, amelanotic, metastatic, and in-transit melanomas. The nuclear staining pattern of Mitf is compared at low and high powers. This amelanotic tumor was also negative for HMB-45 but was positive for Mitf and S-100 (Figure 3). Mitf also stained positively in a melanoma-intransit (Figure 3). This invasive tumor resides in the dermal/subdermal region without contiguous extension from overlying epidermis.

Several specific clinical scenarios are shown in Figure 4 highlighting instances in which Mitf may display particular diagnostic utility. An HMB-45-negative melanoma is shown (Figure 4, column A) in which nuclear staining for Mitf is observed. Another tumor was HMB-45-positive only in the in situ component (Figure 4, column B, arrow), but HMB-45-negative within the invasive component (Figure 4, column B labeled invasive). In contrast, Mitf staining was positive in both the in situ and invasive compo- nents of this tumor (Figure 4, column B). One of the S-100-negative tumors shown (Figure 4, column C) was also negative for $\mathrm{HMB}-45$. It, too, stained positively for Mitf. Finally, a melanoma is shown in which the Mitf stain permitted detection of invasive tumor cell clusters deep within the sample that might otherwise have been missed (Figure 4, column D, arrow).

To assess the specificity of Mitf expression among nonmelanoma tumors, 60 randomly selected nonmelanocytic tumors were stained for Mitf (Table 2). These samples comprised 10 invasive ductal carcinomas of the breast, 10 squamous cell carcinomas of the lung, 10 endometrial adenocarcinomas, 10 thyroid carcinomas, 10 vulvar squamous cell carcinomas, and 10 testicular carcinomas. S-100 has been shown to be expressed in 20 to $40 \%$ of these tumors. ${ }^{28,38}$ The same tumors were also stained for HMB-45. Of these 60 tumors, 58 were negative for Mitf staining, and the remaining two (both breast carcinomas) displayed a cytoplasmic rather than nuclear staining pattern. Only one thyroid carcinoma dis- 


\section{HMB-45 neg}
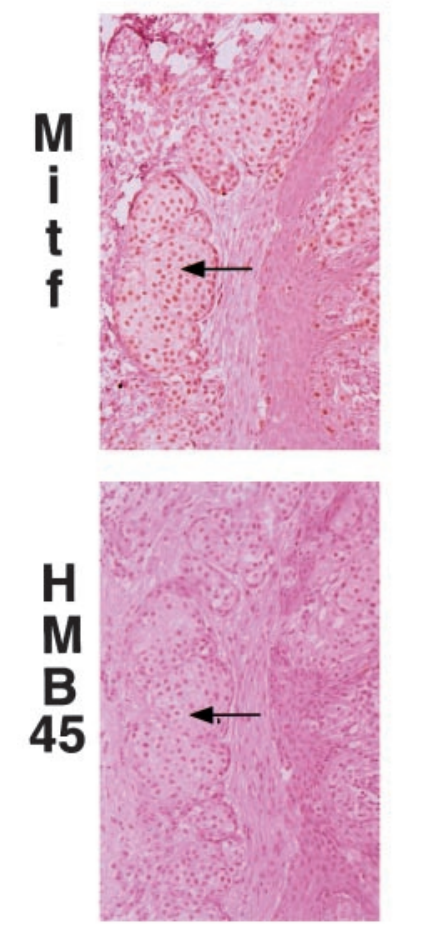

A
HMB-45 in situ selective
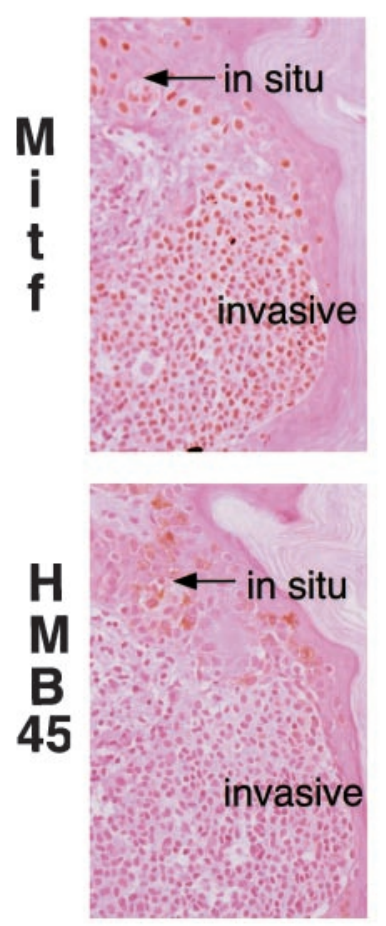

B

\section{S-100 neg deep staining}
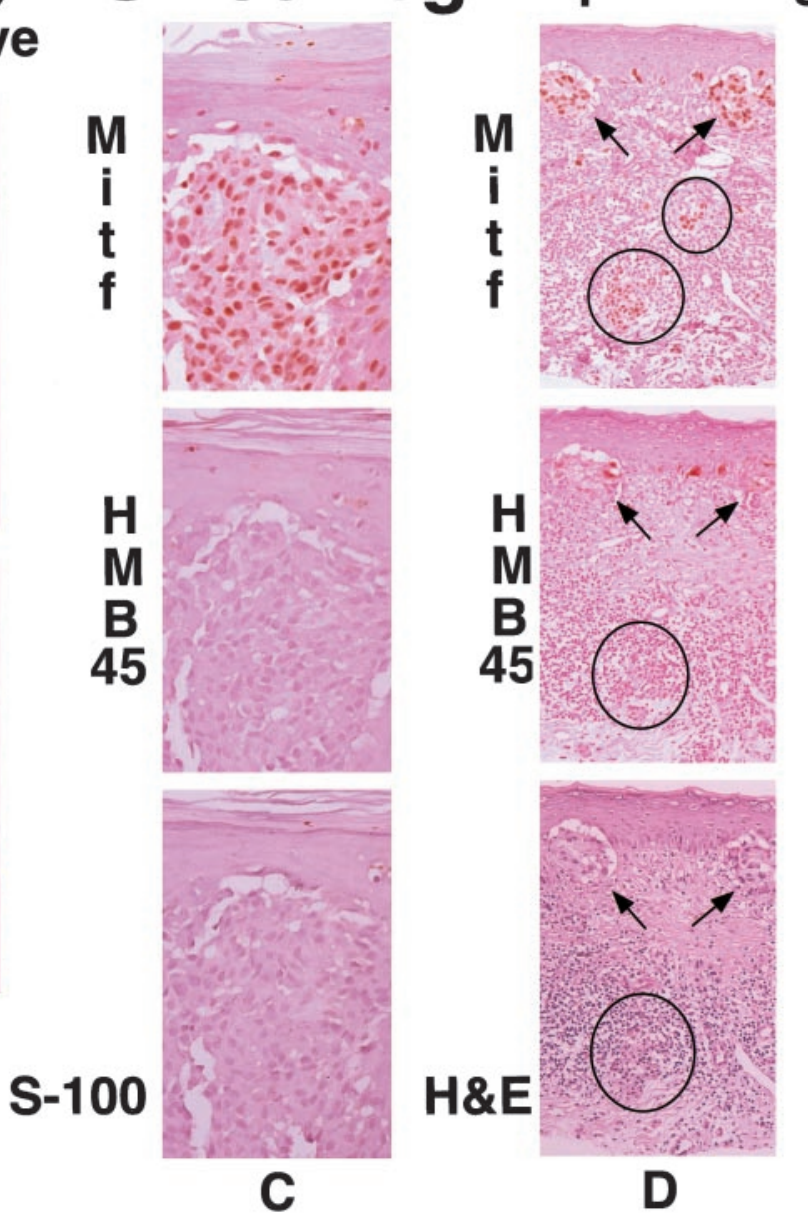

Figure 4. Mitf staining of S-100-negative and HMB-45-negative melanomas. A: HMB-45 neg refers to a conventional melanoma that was negative for HMB-45, but positive for Mitf (arrow). B: HMB-45 in situ-selective (original magnification, $\times 45$ ) is a case in which HMB- 45 staining was positive within the in situ component (small arrow), but not the invasive melanoma component (invasive) while Mitf stained both the in situ (small arrow) and invasive components. C: S-100 neg (original magnification, $\times 60$ ) refers to a case in which Mitf was positive, but HMB- 45 and S-100 were negative. D: Deep staining (original magnification, $\times 10$ ) refers to a case in which Mitf staining identified melanoma nests deep in the dermis (circles) that were not easily appreciated by H\&E or HMB-45.

played focal HMB-45 immunostaining; the remaining 59 cases were HMB-45-negative. Thus, Mitf stained cytoplasms in 2 of 60 nonmelanomas, but no cases exhibited nuclear staining.

Table 2. Mitf and HMB-45 Staining Characteristics in Common Nonmelanoma Tumors

\begin{tabular}{lll}
\hline & $\begin{array}{c}\text { Mitf }+ \\
(\% \text { positive })\end{array}$ & $\begin{array}{c}\mathrm{HMB}-45+ \\
(\% \text { positive })\end{array}$ \\
\hline $\begin{array}{l}\text { Nonmelanoma tumors } \\
\text { Invasive ductal breast } \\
\quad \text { carcinoma }\end{array}$ & $0 / 10^{*}$ & $0 / 10$ \\
$\quad$ Squamous carcinoma lung & $0 / 10$ & $0 / 10$ \\
$\quad$ Endometrial & $0 / 10$ & $0 / 10$ \\
$\quad$ adenocarcinoma & $0 / 10$ & $1 / 10$ \\
$\quad$ Thyroid carcinoma & $0 / 10$ & $0 / 10$ \\
$\quad$ Squamous carcinoma & & \\
$\quad$ vulva & $0 / 10$ & $0 / 10$ \\
$\quad$ Testicular cancer & $0 / 60(0)$ & $1 / 60(2)$ \\
\hline All nonmelanomas in series &
\end{tabular}

${ }^{*}$ Two of the 10 breast cancer cases showed cytoplasmic but no nuclear staining for Mitf.

\section{Discussion}

In this series of 76 consecutively accessioned, histologically confirmed melanomas, the Mitf antibody detected $100 \%$ of cases. S- 100 and HMB-45 failed to detect 5 and 7 cases, respectively, of the 76 melanomas. Mitf also identified an area of deep dermal staining on a specimen that was difficult to visualize with $H \& E$ and negative with HMB-45 staining. This deep staining may confer a worse prognosis because it would alter the measured thickness of the tumor and thereby alter treatment decisions about, eg, optimal surgical margins and/or adjuvant therapy. Mitf is also a specific antibody, staining nuclei in none of 60 nonmelanomas, though staining cytoplasms in 2. Compared to current standard immunological markers of melanoma, Mitf is more specific than S-100 and is as sensitive, if not more so, than HMB-45 in these histologically confirmed cases.

Mitf staining in melanomas produces a nuclear pattern which has some theoretical advantages over cytoplasmic immunostains. It may be difficult to distinguish back- 
ground staining from positivity for cytoplasmic antibodies, especially with weak signal. Furthermore, cellular architecture is not obscured with nuclear staining, which aids in the preservation of the tissue structure being examined. For pigmented lesions it may be difficult to distinguish cytoplasmic stains from pigmentation, although such lesions are less likely to require special stains.

Mitf was expressed in $8 / 8$ histologically amelanotic melanomas. Based on its recognition of the $\mathrm{M}$ box promoter element, ${ }^{5}$ Mitf is thought to regulate transcription of the pigmentation enzymes tyrosinase, TRP1 and TRP2. ${ }^{5-7}$ Its persistent expression in the amelanotic melanomas examined here suggests that factors downstream of Mitf may down-regulate pigmentation. One such mechanism is the proteolytic degradation of tyrosinase, recently described for human melanoma cells. ${ }^{25}$ These findings suggest that down-regulation of pigmentation may occur through mechanisms downstream of Mitf rather than through loss of Mitf itself. Of note, however, nondetection of Mitf expression at the RNA level has been observed in a murine amelanotic melanoma cell line. ${ }^{15}$

Mitf was consistently detected in all metastatic melanomas in this series. Although the broader clinical utility of Mitf for metastatic melanoma remains to be validated with larger trials, these data using histologically confirmed melanoma specimens suggest that Mitf may be a sensitive marker for this clinical entity, which can represent a diagnostic challenge. From 4 to $14 \%$ of melanomas have no known primary site, arise from an internal site, or are diagnosed at the metastatic stage. ${ }^{18-22}$ Moreover, because a significant fraction of metastatic melanomas are amelanotic, such lesions may be difficult to classify on simple morphological grounds, certainly to the nonspecialist, and could represent a variety of undifferentiated or poorly differentiated tumors such as epithelial tumors, sarcomas, lymphoid neoplasms, or germ cell tumors. ${ }^{39}$ Combined detection of S-100 and keratin may help rule in or rule out the possibility a melanoma. S-100 is sensitive for melanoma but also commonly stains other tumors in this differential including breast adenocarcinomas, lung carcinomas, teratomas, neurogenic tumors, and others, ${ }^{23,29,40-43}$ whereas keratin expression is atypical in melanomas. ${ }^{44}$ Larger survey studies are still needed to determine the true specificity of Mitf staining in diverse malignancies as well as in metastatic melanoma.

It is noteworthy that 2 of the breast cancer specimens in this series produced cytoplasmic Mitf staining. Mitf is normally expressed in osteoclasts and mast cells, and it is known that many breast cancers express genes involved in bone resorption such as parathyroid hormonerelated protein, cathepsin K, interleukin-6, interleukin-1, transforming growth factor, and collagenases. ${ }^{45,46}$ It will be of interest to examine mast cell and osteoclastic lesions for Mitf expression. If the staining of the breast lesions reflects true Mitf protein expression, it is possible that this Mitf protein might up-regulate osteoclast-like genes such as cathepsin $\mathrm{K}$, a resorption factor recently detected in breast tumor cell lines. ${ }^{47}$ As such, Mitf ex- pression could play a role in bone metastasis of breast cancer and perhaps even predict osteotrophic tumors.

HMB-45 antibody recognizes the melanosome matrix protein pmel 17 or gp100., 30,48 Like Mitf, HMB-45 antibody recognizes a melanocyte antigen and is not thought to discriminate between melanocytes and melanoma cells. Mitf is thought to represent a central transcriptional regulator of enzymes involved in melanin biosynthesis. Because all HMB-45-positive tumors in this series also expressed Mitf, it is possible that Mitf regulates the transcription of pmel 17 , a possibility consistent with prior studies of these factors. ${ }^{15}$

These results demonstrate that microphthalmia is a sensitive and specific melanocyte marker for melanoma diagnosis. Mitf also appears to be a master regulator of both melanocyte development and postnatal viability, as well as pigmentation. The preservation of Mitf expression in melanomas is consistent with the possibility that it could play a role in melanoma cell survival. If so, an understanding of its biochemical roles may result in its use as a therapeutic target.

\section{Acknowledgments}

We thank Dr. Ruth Halaban for the gift of the melanoma cell lines 501-mel, YUZAZ6, and MeWo, and for useful advice and discussion; Drs. Scott Granter, Glenn Dranoff, and Roydon Price for useful discussions; and Rachel Karlip for secretarial assistance.

\section{References}

1. Silver WK: The Coat Colors of Mice: A Model for Mammalian Gene Action and Interaction. New York, Spinger-Verlag, 1979

2. Hughes AE, Newton VE, Liu XZ, Read AP: A gene for Waardenburg syndrome type 2 maps close to the human homologue of the $\mathrm{mi}$ crophthalmia gene at chromosome 3p12-p14.1. Nat Genet 1994, 7:509-512

3. Tassabehji M, Newton VE, Read AP: Waardenburg syndrome type 2 caused by mutations in the human microphthalmia (MITF) gene. Nat Genet 1994, 8:251-255

4. Hodgkinson CA, Moore KJ, Nakayama A, Steingrimsson E, Copeland $N G$, Jenkins NA, Arheim $\mathrm{H}$ : Mutations at the mouse microphthalmia locus are associated with defects in a gene encoding a novel basichelix-loop-helix-zipper protein. Cell 1993, 74:395-404

5. Hemesath TJ, Steingrimsson E, McGill G, Hansen MJ, Vaught J, Hodgkinson CA, Armheiter $\mathrm{H}$, Copeland NG, Jenkins NA, Fisher DE: Microphthalmia, a critical factor in melanocyte development, defines a discrete transcription factor family. Genes Dev 1994, 8:2770-2780

6. Yasumoto K, Yokoyama K, Shibata K, Tomita Y, Shibahara S: Microphthalmia-associated transcription factor as a regulator for melanocyte-specific transcription of the human tyrosinase gene. Mol Cell Biol 1994, 14:8058-8070

7. Bentley NJ, Eisen T, Goding CR: Melanocyte-specific expression of the human tyrosinase promoter: activation by the microphthalmia gene product and role of the initiator. Mol Cell Biol 1994, 14:79968006

8. Bertolotto C, Abbe P, Hemesath TJ, Billek, Fisher DE, Ortonne JP Ballotti R: Microphthalmia gene product as a signal transducer in cAMP-induced differentiation of melanocytes. J Cell Biol 1998, 142 : 827-835

9. Price ER, Horstmann MA, Wells A, Weilbaecher K, Takemoto C Landis M, Fisher D: $\alpha \mathrm{MSH}$ signaling regulates expression of microphthalmia, a gene deficient in Waardenburg Syndrome. J Biol Chem 1998, 273:33042-33047 
10. Lerner $A B$, Shibahara $T$, Boissy RE, Jacobson $K A$, Lamoreux $M L$, Moellmann GE: A mouse model for vitiligo. J Invest Dermatol 1986, 87:299-304

11. Steingrimsson E, Moore KJ, Lamoreux ML, Ferre D, Burley S, Zimring D, Skow L, Hodkinson C, Arnheiter H, Copeland N, Jenkins N: Molecular basis of mouse microphthalmia (mi) mutations helps explain their developmental and phenotypic consequences. Nat Genet 1994, 8:256-263

12. Hemesath TJ, Price ER, Takemoto C, Badalian T, Fisher DE: MAP kinase links the transcription factor microphthalmia to $c-K i t$ signalling in melanocytes. Nature 1998, 391:298-301

13. Price ER, Ding H-F, Badalian T, Bhattacharya S, Takemoto C, Yao T, Hemesath T, Fisher D: Lineage-specific signaling in melanocytes. J Biol Chem 1998; 273:17983-17986

14. Sato S, Roberts K, Gambino G, Cook A, Kouzarides T, Goding CR: $\mathrm{CBP} / \mathrm{p} 300$ as a co-factor for the microphthalmia transcription factor. Oncogene 1997; 14:3083-3092

15. Halaban R, Bohm M, Dotto P, Moellmann G, Cheng E, Zhang Y: Growth regulatory proteins that repress differentiation markers in melanocytes also downregulate the transcription factor microphthalmia. J Invest Dermatol 1996, 106:1266-1272

16. Barth A, Wanek LA, Morton DL: Prognostic factors in 1,512 melanoma patients with distant metastases. J Am Coll Surg 1995, 181:193-201

17. Evans GRD, Manson PN: Review and current perspectives of cutaneous malignant melanoma. J Am Coll Surg 1994, 178:523-540

18. DeVita V, Hellman S, Rosenberg S: Cancer: Principles and Practice of Oncolgoy. Vol. 2. Philadelphia, JB Lippincott Company, 1993, pp 2072-2092

19. Chang $P$, Knapper W: Metastatic melanoma of unknown primary Cancer 1982, 49:1106-1111

20. Jonk A, Kroon B, Rumke P, Mooi W, Hart A, Van Dongen J: Lymph node metastasis from melanoma with an unknown primary site. $\mathrm{Br} \mathrm{J}$ Surg 1990, 77:665-668

21. Reintgen D, McCarty K, Woodard B, Cox E, Seigler H: Metastatic malignant melanoma with an unknown primary. Surg Gynecol Obstet 1983, 156:335-340

22. Schlagenhauff B, Stroebel W, Ellwanger U, Meier F, Zimmermann C, Breuninger C, Rassner G, Barbe C: Metastatic melanoma of unknown primary origin shows prognostic similarities to regional metastatic melanoma: recommendations for initial staging examinations. Cancer 1997, 80:60-65

23. Kaufmann O, Koch S, Burghard J, Audring H, Dietel M: Tyrosinase, Melan-A, and KBA62 as markers for the immunhistochemical identification of metastatic amelanotic melanomas on paraffin sections. Mod Pathol 1998, 11:740-746

24. Zakut R, Perlis R, Eliyahu S, Yarden Y, Givol D, Lyman S, Halaban R: Kit ligand (mast cell growth factor) inhibits the growth of kit-expressing melanoma cells. Oncogene 1993, 8:2221-2229

25. Halaban R, Cheng E, Zhang Y, Moellmann G, Hanlon D, Michalak M, Setaluri M, Hebert D: Aberrant retention of tyrosinase in the endoplasmic reticulum mediates accelerated degradation of the enzyme and contributes to the dedifferentiated phenotype of amelanotic melanoma cells. Proc Natl Acad Sci USA 1997, 94:6210-6215

26. Carrel S, Rimoldi D: Melanoma-associated antigens. Eur J Cancer 1993, 29A:1903-1907

27. Rossi C, Foletto A, Vecchiato S, Alessio N, Menin N, Lise M: Management of cutaneous melanoma MO: state of the art and trends. Eur J Cancer 1997, 33:2302-2312

28. Cochran A, Wen D: S-100 protein as a marker for melanocytic and other tumors. Pathology 1985, 17:340-345
29. Orchard G, Jones E: Immunocytochemistry in the diagnosis of malignant melanoma. Br J Biomed Sci 1994, 51:44-56

30. Bacchi C, Bonetti F, Pea M, Martignoni G, Gown A: HMB-45. Appl Immunhistochem 1996, 4:73-85

31. Kahn H, Marks A, Thom H, Baumal R: Role of antibody to $S 100$ protein in diagnostic pathology. Am J Clin Pathol 1983, 79:341-347

32. Busam K, Chen Y, Old L, Stockert E, Iversen K, Copeland KA, Rosai J, Barnhill R, Jungbluth AA: Expression of Melan-A (MART1) in benign melanocytic nevi and primary cutaneous malignant melanoma. Am J Surg Pathol 1998, 22:976-982

33. Elenitsas R, Schuchter $\mathrm{L}$ : The role of the pathologist in the diagnosis of melanoma. Curr Opin Oncol 1998, 10:162-169

34. Skelton H, Maceira J, Smith K, McCarthy W, Lupton G, Graham J: HMB-45 negative spindle cell malignant melanoma. Am J Dermatopathol 1997, 19:580-584

35. Gown A, Vogel A, Hoak A, Gough F, NcNutt M: Monoclonal antibodies specific for melanocytic tumors distinguish subpopulations from melanocytes. Am J Pathol 1986, 123:195-203

36. Cohen T, Gitay-Gorey H, Sharon R, Shibuya M, Halaban R, Levi B, Neufeld G: VEGF121, a vascular endothelial growth factor (VEGF) isoform lacking heparin binding ability, requires cell-surface heparan sulfates for efficient binding to the VEGF receptors of human melanoma cells. J Biol Chem 1995, 270:1132-1136

37. Weilbaecher KN, Hershey CL, Takemoto CM, Horstmann M, Hemesath T, Tashjian A, Fisher D: Age-resolving osteopetrosis: a rat model implicating microphthalmia and the related transcription factor TFE3. J Exp Med 1998, 187:775-785

38. Herrera G, Turbat-Herrera E, Lott R: S-100 protein expression by primary, and metastatic adenocarcinomas. Am J Clin Pathol 1998, 89:168-176

39. Ackerman L: Surgical Pathology. Vol. 1. St. Louis, Mosby, 1953, p 115

40. Schmitt F, Bachhi C: $S 100$ protein: is it useful as a tumour marker in diagnostic immunocytochemistry? Histopathology 1989, 15:281-288

41. Stefansson K, Wollmann R, Jerkovic M: S100 protein in soft-tissue tumours dervied from schwann cells and melanocytes. Am J Pathol 1982, 106:261-268

42. Guillermo A, Herrera E, Turbat-Herrera A: S100 protein expression by primary and metastatic adenocarcinomas. Am J Clin Pathol 1988, 89:168-176

43. Drier J, Swanson P, Cherwitz D, Wick M: S-100 protein immunoreactivity in poorly differentiated carcinomas: immunohistochemical comparison with malignant melanoma. Arch Pathol Lab Med 1987, 111: 447-452

44. Zarbo R, Gown A, Visscher D, Crissman J: Anomolous cytokeratin expression in malignant melanoma: one and two dimensional Western blot analysis and immunohistochemical survey of 199 melanomas. Mod Pathol 1990, 3:494-501

45. Yoneda T, Sasaki A, Mundy G: Osteolytic bone metastasis in breast cancer. Breast Cancer Res Treat 1994, 32:73-84

46. Scher H, Yagoda A: Bone metastases: pathogenesis, treatment and rationale for use of resorption inhibitors. Am J Med 1987, 82:6-28

47. Littlewood-Evans A, Bilbe G, Bowler W, Farley D, Wlordski B, Kokubo T, Inaoka T, Sloane J, Evans D, Gallager J: The osteoclast-associated protease cathepsin $\mathrm{K}$ is expressed in human breast carcinoma. Cancer Res 1997, 57:5386-5390

48. Kwon BS: Pigmentation genes: the tyrosinase gene family and the pmel 17 gene family. J Invest Dermatol 1993, 100:134S-140S 